\title{
Examining the Types of Mathematical Tasks Used to Explore the Mathematics Instruction by Elementary School Teachers
}

\author{
Wei-Min Hsu \\ Graduate Institute of Mathematics and Science Education, National Pingtung University of Education, \\ Pingtung, Taiwan \\ Email: ben8535@mail.npue.edu.tw
}

Received April $1^{\text {st }}$, 2013; revised May $4^{\text {th }}$, 2013; accepted May $15^{\text {th }}$, 2013

\begin{abstract}
Copyright (c) 2013 Wei-Min Hsu. This is an open access article distributed under the Creative Commons Attribution License, which permits unrestricted use, distribution, and reproduction in any medium, provided the original work is properly cited.
\end{abstract}

\begin{abstract}
This study examined the different types of mathematical tasks used in the classroom to explore the nature of mathematics instruction of three sixth grade teachers in an elementary school. Case studies, instructional observations, and classroom artifacts were used to collect data. The results showed that the three teachers used different types of mathematical tasks and implementation methods. One teacher focused on high cognitive demand tasks, most of which involved substantial group discussion and students working cooperatively. Even though the other two also used many high cognitive demand tasks, these were mainly presented via teacher-student dialogue. By examining the types of mathematical tasks and their implementation, it was found that the group discussion tasks were generally all high cognitive demand tasks, in which the students fully explained the solution process. As for the tasks administered through teacherstudent dialogue, due to the usage of large amounts of closed-ended dialogue, the students used low cognition to solve the mathematical tasks and did not have the opportunity to completely explain their thinking about the solutions. Thus, in order to fully understand the nature of mathematics instruction by teachers, there should be simultaneous consideration of the types of mathematical tasks used as well as how the tasks were implemented.
\end{abstract}

Keywords: Mathematics Instruction; Mathematical Tasks; Task Implementation

\section{Introduction}

Mathematics instruction in the classroom is the key to understanding student learning in mathematics (Boaler \& Staples, 2008; Gutstein, 2003; Henningsen \& Stein, 1997; Mullis, Martin, Gonzales, \& Chrostowski, 2004; Stein, Remillard, \& Smith, 2007). However, exactly what does classroom mathematics instruction involve? How should one seek to understand and analyze this instruction in the classroom? Hiebert and Grouws (2007) believed that instruction is comprised of student-teacher interactions in the classroom based on the learning of content, and that the purpose of teacher-student interaction is to achieve specific learning objectives. Seen from this perspective, there are two key focuses of classroom mathematics instruction, the first is the learning content and the second is the interaction between teachers and students regarding the content. For mathematics, the content to be learned refers to concepts and capabilities associated with numbers and measurement, algebra, geometry, statistics, and probability (Ministry of Education in Taiwan, 2003; NCTM, 2000), which are usually presented in textbooks in the form of mathematical tasks (Henningsen \& Stein, 1997; Stein et al., 2007). At the same time, since the reform of mathematics instruction in the 1980s, teachers have emphasized allowing students to learn and understand mathematical concepts via the mathematical tasks they provide, tasks whereby students have opportunities to apply their mathematiccal abilities and techniques (Cowan, 2006). In addition, research has shown that the mathematics instruction provided by teachers generally focuses on students learning from the mathematical tasks in the textbook (Grouws, Smith, \& Sztajn, 2004). Thus, it is clear that mathematics instruction in the classroom focuses on mathematical tasks, and the implementation of these tasks typically involves teacher-student interaction in order to facilitate mathematics learning. Hence, the implementation of mathematical tasks in the classroom is a productive way to explore the mathematics instruction of teachers.

A number of studies have focused on using mathematical tasks to explore and analyze the instructional performance of teachers. Henningsen and Stein (1997), for example, used the types of and the implementation of mathematical tasks to explore their influence on teaching methods and their results on student mathematics learning. Artzt and Armour-Thomas (2002) used the mathematical tasks provided, the learning environment created, and the student-teacher interaction to analyze teacher performance in mathematics instruction. Silver, Mesa, Morris, Star and Benken (2009) used the types of mathematical tasks and the instructional characteristics adopted by the teachers in the classroom to understand the relationship between the mathematics instruction of the teachers and the students' learning. These studies all productively used the types of and the 
implementation of mathematical tasks by teachers in the classroom to explore the instructional performance of the teachers. The types of mathematical tasks can be categorized into low cognitive demand and high cognitive demand, based on the cognitive demands required of the students when solving the tasks, and it has been shown that these different tasks produce different implementation methods (Stein, Smith, Henningsen, \& Silver, 2000). After several instances of mathematics curricular reform, middle and elementary schools in Taiwan have moved from emphasizing knowledge acquisition and knowledge construction to the cultivation of abilities (Chung, 2005); at the same time instruction has turned from the previous emphasis on mathematical knowledge structure, basic computational techniques and practicing routine tasks, to emphasizing the active construction of mathematical knowledge, thus creating a balance between conceptual understanding and adept calculations. These changes have not only affected the presentation of mathematical tasks in textbooks but have also affected the implementation of these mathematical tasks in the classrooms. However, research has found that when teachers face mathematics instruction reform, they often show a resistance to changing their instruction (Rodriguez, 2005). Teacher instruction is still fundamentally based on traditional lectures that utilize low cognitive demand mathematical tasks (Boaler \& Brodie, 2004; Weiss, Banilower, McMahon, \& Smith, 2001). Thus, the type of and the implementation of mathematical tasks by teachers after nearly 20 years of mathematical curriculum and instruction reform in Taiwan are worthy of study. This study would like to combine with the types of and implementation methods of mathematical tasks to develop a rich description and deep understanding of mathematics instruction in the classroom, which can in turn be used for further explorations of mathematics classroom instruction in Taiwan.

\section{Literature Review}

\section{Trends and Related Observations in Mathematics Instruction}

In the first half of the 20th century, mathematics instruction in Taiwan generally followed the three rules of learning proposed by Thorndike, which emphasized the connection between stimulation and response. Subsequently, the perspective of constructivism in learning has become widely accepted. In this perspective students' preexisting knowledge and experience are emphasized, as well as the importance of active learning in order to achieve mathematics learning with understanding (Willoughby, 2000). In general terms, the trend of mathematics reform in various countries has changed the perspective on the learner to that of an individual actively constructing mathematical knowledge (Becker \& Selter, 1996; NCTM, 2000). At the same time, in a high-tech and rapidly changing society, students are no longer merely required to have basic techniques but also need to develop abilities in areas such as diverse viewpoints, leadership, interpersonal relationships, team work and adaptability (Lott \& Souhrada, 2000). Thus, mathematics instruction at school not only covers mathematical concepts and computational abilities but also student communication, problem-solving, deduction, and evaluation (Ministry of Education, 2003; NCTM, 2000), in order to attend to the future needs of life and society.

In summary, changes in the perspectives on the learning process have caused mathematics instruction to focus on stu- dent learning emphasizing student-centered approaches in order to promote student mathematics comprehension (Kilpatrick \& Silver, 2000; NCTM, 2000). Classroom activities in mathematics instruction are no longer merely based on an information transmission model; they now seek to create an environment that stimulates student thinking, provides learning and problemsolving activities, and provides guidance and support for problem-solving (Verschaffel \& De Corte, 1996). Feldman (2003) pointed out that mathematics instruction should provide suitable mathematical challenges, as well as assistance and strategies during the learning process to help student learning. Fuson et al. (2000) further proposed that mathematics instruction should begin with what is meaningful to the students, in order to develop a culture based on comprehension and mutual assistance in cooperative mathematics dialogues. Anderson (2003) added that the focus of mathematics instruction should be on student thinking, and that the development of fair learning communities to achieve mathematics instruction with comprehension should be the target. Seen from these trends and observations of mathematics instruction, it is possible to understand that the current types of and methods for administering mathematical tasks in the classroom should be based on providing meaningful and suitably challenging mathematical tasks to students in a cooperative dialogue environment.

\section{Types of Tasks and Methods of Task Implementation}

Mathematical tasks include the problems and practice activities used by teachers in the mathematics classroom. A mathematical task will take up a certain work period in the classroom, during which students are expected to work hard at learning specific mathematical concepts (Henningsen \& Stein, 1997). Based on this definition, mathematical tasks may be simple equations, word problems, or measurement activities. The cognitive demand required of the students when solving tasks can be classified into four levels: memorization, procedures without connections, procedures with connections, and doing mathematics (Stein et al., 2000). For mathematical tasks that involve memorization or procedures without connections, the students only need to employ rote memorization or mechanical use of rules to successfully solve the tasks. They do not need real comprehension of concepts involved. These two types of tasks are considered low cognitive demand tasks, because they do not much cognitive demand on the students. As for tasks involving procedures with connections or doing mathematics, these are high cognitive demand tasks that require real comprehension of concepts and ideas as well as the selection of suitable strategies, including engaging in deduction, induction, and proof, in order to solve the tasks. For example, low cognitive demand tasks often focus on recall of basic facts and proficiency in computational techniques, whereas high cognitive demand tasks emphasize solving, deducing, and applying. Examples of the four types of different mathematical tasks are shown in Table 1.

Different types of mathematical tasks tend to lead to differences in teacher-student interaction and in how the tasks are presented in the classroom. Low cognitive demand mathematical tasks emphasize using memorized formulas or relationships to solve problems and require proficiency in computational procedures; thus, unidirectional or closed methods are the norm for teacher-student interaction. High cognitive demand mathematical tasks involve more complex information and mental processing and thus require students to create problem-solving 
Table 1.

Examples of the four types of mathematical tasks.

\begin{tabular}{ll}
\hline Task type & Example and possible response from students \\
\hline Memorization & $\begin{array}{l}\text { What are the fractions and percentages equal to } \\
1 / 2 \text { ? (Write out the answers immediately based } \\
\text { on the definition) }\end{array}$ \\
$\begin{array}{l}\text { Convert 3/8 to a fraction and a percentage. } \\
\text { Procedures without } \\
\text { connections }\end{array}$ & $\begin{array}{l}\text { (Find the answer through computational } \\
\text { procedures) }\end{array}$ \\
Procedures with & $\begin{array}{l}\text { Use the hundred cell board to mark fractions and } \\
\text { percentages equal to 3/5. (Need to connect } \\
\text { representations) }\end{array}$ \\
& $\begin{array}{l}\text { In a } 4 \times 10 \text { cell board, shade in } 6 \text { cells, and then } \\
\text { explain how to determine the percentage and } \\
\text { fraction of the shaded surface. (Need to select } \\
\text { suitable methods to solve and explain) }\end{array}$ \\
Doing mathematics
\end{tabular}

Note: Modified from Implementing standards-based mathematics instruction: A casebook for professional development (p. 13), by Stein et al., 2000, NY: Teacher College. The content in parentheses shows possible student responses.

methods and use a deep understanding of mathematical concepts during the process of thinking, discussing, and exploring (Silver et al., 2009). Thus, open and bidirectional interactive methods can be used to provide students with more opportunities to explore, interpret, and explain the concepts. For low cognitive demand mathematics tasks, implementation is often based on teacher lecture, and the learning focus is generally on developing proficiency of problem-solving techniques. The presentation of high cognitive demand tasks is primarily based on discussion and cooperative problem-solving. In addition to understanding concepts, the learning focus is also on the cultivation of abilities in thinking, communication, and logic (Stein et al., 2007). This shows that the type of mathematical task not only affects the learning focus but also the instructional implementation.

However, the type of mathematical task cannot be used to singularly determine the implementation methods used in the classroom, because the presentation methods may differ from the original demands of the mathematical task type. Henningsen and Stein (1997) found that mathematical tasks that were originally high cognition tasks might be simplified due to an improper time distribution, a lack of suitable learning motivation, a lack of the students' preexisting knowledge, or class management issues. Boaler and Brodie (2004) found that in both traditional and revised mathematics textbooks, teachers generally focused on lecturing about rules and procedures. The TIMSS 1999's instructional video research showed that although $17 \%$ of the mathematical tasks selected by teachers for use in instruction were high cognitive demand tasks, they were implemented as procedural practices (Stein et al., 2007). Thus, the exploration and understanding of mathematics instruction teachers requires not only identifying and understanding the types of mathematical tasks used in the classroom, but also examining the implementation of the mathematical tasks.

\section{Methodology}

\section{Method}

Previous research or literature has pointed out that the implementation of mathematical tasks by teachers in the classroom is a complex and highly personalized process (Henningsen \& Stein, 1997; Stein et al., 2007). At the same time, few studies have focused on the classroom implementation of mathematical tasks to analyze and explore teacher mathematics instruction (such as Silver et al., 2009). Highly personalized complex processes and research issues for initial exploration should be examined using case studies. This research presents case studies on three sixth-grade teachers with different backgrounds. Video recordings were made and documents were collected during the course of one semester, in order to understand the types of and implementation methods of the mathematical tasks used by the teachers in the classroom. These two data sources were analyzed to understand the mathematics instruction demonstrated by the case teachers. Past assertions in the literature about trends in mathematics instruction, including the classifications of the types of mathematical tasks, the implementation methods and their relationships, were all used as references for data collection and analysis.

\section{Subjects}

This study selected three sixth-grade teachers with different academic and teaching experience, as well as different teaching locations, as the case study subjects. Pseudonyms were given to the teachers to protect their identity. Lian had 15 years of instructional experience, had majored in education at university, was teaching at an urban school, and had worked as a mathematics instruction counselor for one year. Mike had six years of instructional experience, had majored in mathematics at university, was teaching at an urban school, and had five years of teaching experience at a mathematics cram school. Yan had nine years of instructional experience, had majored in mathematics at university, was teaching at a rural school, and had worked as an information instruction counselor for three years. In the past, Lian's mathematics instruction had mixed group discussions and teacher lectures, depending upon student learning performance. Mike and Yan primarily used lectures as their instructional method. The three teachers all stated that their mathematics instruction considered course progress, the results of student evaluations, and school policy.

\section{Data Collection}

The period of data collection in this study was from February 2009 to June 2009. Instructional observation videos and document records were primarily used to collect data, which was compared with definitions in the literature in order to understand the mathematics tasks and methods administered by the teachers. At the same time, the possible relationships between the tasks and the implementation methods of mathematics tasks were considered. In the following, the methods and focuses of the different data collection methods are explained, as well as their relationship with the research purpose.

In order to understand how the three teachers presented mathematical tasks in their classrooms, instructional observations and video recordings were used to collect data. One class was recorded each week for each teacher during the chosen semester. Not counting the three examination weeks, and the early conclusion of the course for the sixth grade, each case teacher was observed and video recorded 12 or 13 times. The observed instructional units included 7 - 8 units about numbers and measurement, algebra, geometry and statistics. The observed content was not the same for each unit. Sometimes the first class for a unit was observed, and sometimes it was a middle class or the last class of a unit. In other words, the content 
observed for the three teachers covered different mathematical topics and was observed in different orders, in order to represent the overall implementation of the mathematical tasks by the teachers. The focus of the instructional observations followed the suggestions by Stein et al. (2007) and Silver et al. (2009), where in addition to coding the types of mathematical tasks used by the teachers in the classroom, the activities used when presenting the mathematical tasks and the methods of teacher-student interaction were also recorded in order to understand the purposes of the teachers' implementation of the mathematical tasks.

Document collection refers to collecting the problem-solving records left by students when they participate in problem-solving activities in the classroom. Such paper-pencil records include group or individual problem-solving records (including equations and diagrams), which are then used to compare with and calibrate with other collected data, to understand the focus of the types and implementation of mathematical tasks by teachers.

In addition, after each teacher completed their teaching, semi-structured interviews were immediately conducted focused on the sources of the mathematical tasks used and on the implementation methods employed. Questions such as "Why do you choose this type of task today?" and "Do you usually let students discuss different problem-solving methods?” were used to understand the thinking process of the case teachers in presenting mathematics tasks.

\section{Data Processing and Analysis}

The data collected in this study were primarily instructional observation videos and document records, which were supported by teacher interview data. Each type of data was converted to a text or image for encoding. Encoding was carried out through the principle of person-date-type. Lian, Mike and Yan were denoted by the letters L, M and Y, and the students were represented as S. Dates were encoded as month-date using four digits. The data types were represented using the first two letters of the English word (such as observation = Ob; document $=$ Do), to serve as the basis for future data presentation. As part of analyzing the observation data, counting and summarization of the mathematical tasks was conducted. In counting the mathematical tasks, even though there were different methods of presenting the mathematical tasks (group discussions or teacher-student dialogue), all the case teachers first presented a mathematical task (word problems, diagram problems or simple calculations), and then asked the students to engage in either group discussions, individual problem-solving, or teacher-student dialogue. Thus, one mathematical task was counted as the task presented by the teacher, the interaction based on the task, and the student problem-solving records or answer content. If the teacher repeatedly used dialogue to guide the students in problem solving or in comprehending the same task, but the explored or learned mathematical concept was the same, it was still counted as one task. The following dialogue provides an example:

Y: There is a red banner at the front of the store, which says " $25 \%$ off discount coupon," so Lizhi bought herself a 2400 dollar dress. How much worth of coupon should Lizhi pay? Compare it first, what is the discount?

SS: $75 \%$ off.

Y: Is it $75 \%$ off? ...Is it? Are you sure? Then it would be very cheap.
SS: Yes (some people shook their heads).

Y: S1 is shaking your head, why? What is wrong?

S1: It's not the same as in the front... (dialogue was used to clarify the meaning of "off" in the question, and then the students were asked to individually solve the problem, C0225Ob).

In terms of coding the mathematical tasks, the classification system developed by Stein et al. (2000) was used to divide the tasks into high and low cognitive demand groups, as shown in Table 1. The data used for coding the presenting of mathematical tasks included the teacher-student interaction and class activities associated with the mathematical tasks. As part of the counting and classification of the mathematical tasks, the researchers first clarified the definition of a task and discussed the classification standards, and then individually carried out classification and accounting based on transcripts of the recorded class periods of the three case teachers. Next, the researchers discussed and modified any initial (and different) counting and classification results. The initial results showed that the counting of mathematical tasks was identical, except for Mike. The reason for the difference was that when Mike was guiding students to understand the formulas for volume, he generally used cuboids as examples, and then introduced formulas for trapezoids and triangular prisms, hoping to arrive at the conclusion of cube volume being base surface $\times$ height (M0227Ob). This was originally counted as the trapezoid volume, but after discussion and a comparison of the definition of mathematical tasks, it was thought that this should be counted as one task, because the purpose was to lead to a general principle for the formulas for volume. In terms of classifying the mathematical tasks, there were different interpretations of the requirements for the mathematical tasks used by teachers. For instance, when Mike was leading students toward the volume formulas, one analyst believed that the item emphasized memorization in problem-solving. The other believed that the whole purpose was to lead to common volume formulas, but that it was being done through large amounts of closed-ended dialogue (M0227Ob), so the task itself was still a high cognitive task with connections. After the two analysts reached consensus, they analyzed another class by Mike with greater differences; finally reaching the same conclusion for the counting and classifications of mathematical tasks without further analysis.

The strategy of continued comparison as well as engaging in calibration, categorization, and statistical analysis was used in order to summarize data and theories and to develop a deeper understanding of the types and methods of mathematics tasks administered by teachers.

\section{Results}

\section{Types of Mathematical Tasks Used by the Case Teachers}

Mathematical tasks are classified according to the cognitive demands required when solving them. Formula memorization, definitions, and one-step unit conversions are classified as the memory type, and direct measurement and reading, equation computations (applying known fixed procedures), and singlestep word problems (tasks lacking a challenging character) are classified as having a lack of connection; these two types are both low cognitive demand tasks. Two-step word problems (requiring choices and decisions), open observations and com- 
parisons (requiring comparison and evaluation), and tasks emphasizing the connection between representations are classified as procedures with connections. Doing mathematics requires the students to be liberated from complex context and to have the ability to use suitable strategies and representations; these two types of tasks are both high cognitive demand tasks. In one semester, during 13 periods of observation, Lian administered a total of 37 mathematical tasks, of which 10 were low cognitive demand and 27 were high cognitive demand. Mike administered 32 mathematical tasks, of which 11 were low cognitive demand and 21 were high cognitive demand, and Yan administered 43 mathematical tasks, of which 23 were low cognitive demand and 20 were high cognitive demand. The statistics and different types of mathematical tasks used by the three case teachers are shown in Table 2.

As shown in Table 2 the types of mathematical tasks presented by Lian and Mike focused on high cognitive demand tasks, while Yan focused on low cognitive demand tasks. Neither Mike nor Yan implemented "doing mathematics" types of tasks. Regarding memorization tasks, the three teachers generally presented tasks that required formulas (such as applying volume formulas to find the volume of cubes, M0227Ob) and using definitions to solve problems (such as the definition of the median, L0318Ob, finding the definition of speed, Y0415 Ob). Tasks presented that lacked connections were generally the application of fixed procedures in problem-solving tasks, such as solving equations and reading statistical charts, both of which emphasize using known and fixed procedures to solve problems (such as reading the position of an object using Car- tesian coordinates, $\mathrm{L} 0430 \mathrm{Ob}$, reading the percentage of books borrowed by different classes, M0424Ob) with fewer singlestep word problems that have lower task complexity (such as the statistical amount and pie chart unit, L0312).

Tasks with connections were the ones most frequently implemented by the three teachers. These tasks included open observations and class discussions (such as providing two-dimensional or three-dimensional images so that students can observe regularities, similarities and differences, M0410Ob and Y0408Ob), two-step word problems, and tasks requiring meaningful connections (such as asking for the connection between composite images and equations, L0319Ob). For instance, Yan used pictorial images of building blocks (shown on an electronic whiteboard) so that the students could think about possible solutions. Yan then combined the students' equations and the block images, to verify the meanings of the equations written by the students. At the same time, comparisons of the different equations and images were used so that the students could understand the nature and meaning of the distributive property of multiplication. During the activity, the following

Table 2.

Types of mathematical tasks used by the three case teachers and their presentation methods.

\begin{tabular}{lccc}
\hline Task type & Lian & Mike & Yan \\
\hline Memorization & 1 & 2 & 8 \\
Procedures without connections & 9 & 9 & 15 \\
Procedures with connections & 25 & 21 & 20 \\
Doing mathematics & 2 & 0 & 0 \\
Total & 37 & 32 & 43 \\
\hline
\end{tabular}

dialogue was recorded:

Y: There are two piles of blocks, A and B. There are 12 blocks in $\mathrm{A}$ and 8 in B. Now, there are two types of blocks in the box, 5 piles of A and 5 piles of B. So I ask you, how many blocks are in the box? (Students carry out individual practice, and some are invited to come to the podium).

Y: S1, please explain these equations. What are you calculating in the first equation? (S1's equation is $12 \times 5=$ $60,8 \times 5=40,60 \times 40=100$, S10603Do).

S1: There are 5 piles of 12 blocks, so $12 \times 5 \ldots$

$\mathrm{Y}$ : $\mathrm{OK}$, in his first equation, there are 12 blocks in the $\mathrm{A}$ pile, and there are 5 piles, so all of $\mathrm{A}$ is 60 blocks. Is that what you mean?

S1: (Nods, Yan and S1 verify the meaning of each symbol represented in the equation)...

$\mathrm{Y}$ : Is it possible to combine these three equations into one (S1 shakes head)? S2 please tell us why $12+8$ ? (S2's equation is $(12+8) \times 5=100$, S20603Do).

S2: Add the two piles.

Y: Which two piles do you mean?

S2: A and B.

$\mathrm{Y}$ : one A plus one $\mathrm{B}$, right?

S2: (Nods, Yan and S1 verify the meaning of what each equation means).

$\mathrm{Y}$ : Is there anyone who can explain it more clearly for him? Actually S2 knows what it means, but he doesn't know how to explain it ...

S3: He first calculated the numbers in piles $\mathrm{A}$ and $\mathrm{B}$, then, as there are five piles each, multiplied by 5 .

Y: Can I take this, and take this, and count A and B as one pile... Do you know what I mean? I will show you (opens the electronic white board image, on the top right, and uses icons to explain the equation meanings to students. Irrelevant dialogue is discarded, Y0603Ob).

From examining the paper-pencil solution records of the students, it was possible to better understand the types of mathematical tasks implemented by the teachers. For instance, Lian's implementation of mathematical tasks frequently required the students to write what each equation meant, as well as the connection to the image. For instance, in the composite image surfaces, the students not only showed the connections between the equations and images, there were even groups that thought of repeating the original composite images; after the rectangle surface was subtracted from the semi-circle surface, they could obtain the sum of the two shaded areas (see Figure 1). These thought processes during problem solving were

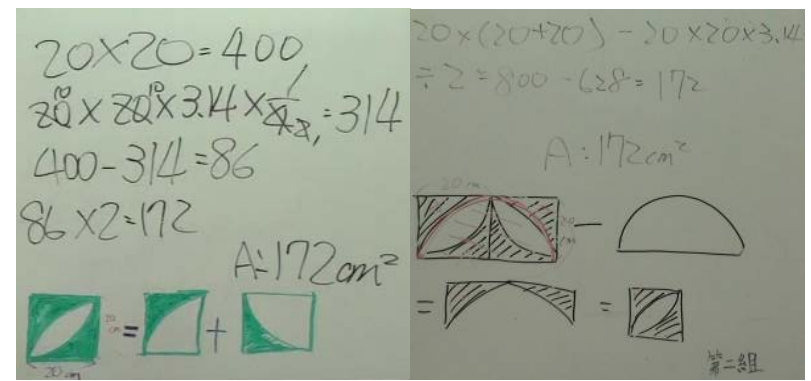

Figure 1.

The paper-pencil solution records of the students. 
praised by the other students (L0319Ob).

Only Lian implemented "doing mathematics" tasks, and these appeared in the commutative property unit about multiplication. One of the problems required the students to substitute numbers into equations in order to illustrate the commutative property in multiplication. Afterwards, Lian further asked the students to list word problems that corresponded to $\mathrm{a} \times \mathrm{b}+$ $\mathrm{c} \times \mathrm{b}$ or $(\mathrm{a}+\mathrm{c}) \times \mathrm{b}$ :

L: who can make a similar word problem? (pointing to the two equations $\mathrm{a} \times \mathrm{b}+\mathrm{c} \times \mathrm{b}$ and $(\mathrm{a}+\mathrm{c}) \times \mathrm{b}$ on the blackboard)

S1: Older brother went to the stationery store to buy b pencils for a dollars each, and also bought b ballpoint pens for c dollars, how much did he need to pay the storeowner?

L: If you use this, what does it mean? (pointing to $\mathrm{a} \times \mathrm{b}+$ $\mathrm{c} \times \mathrm{b}$ on the blackboard).

SS: the two are used to calculate how much each is, and then add them.

L: Which two? How much is each?

SS: Money, the money to pay...

$\mathrm{L}$ : If so, what does it mean? S2, tell me what this means? (pointing to $(\mathrm{a}+\mathrm{c}) \times \mathrm{b}$ on the blackboard).

S2: Add up the prices first, and then multiply it by that..

$\mathrm{L}$ : The price of which?

S2: Add the prices of the pencils and ballpoint pens.

$\mathrm{L}$ : Right, this is the price of one ballpoint pen and one pencil each... this is the price of a ballpoint pen and a pencil (pointing to $(\mathrm{a}+\mathrm{c})$ on the blackboard), this is the sum. So the total you have bought is ... (Irrelevant dialogue is discarded, L0521Ob).

The students needed to first understand the meaning of the equations before they could write the corresponding word problems, so this was classified as "doing mathematics." During the dialogue, Lian confirmed the textual meanings corresponding to the equations and the contextual meanings corresponding to $\mathrm{a} \times \mathrm{b}+\mathrm{c} \times \mathrm{b}$ and $(\mathrm{a}+\mathrm{c}) \times \mathrm{b}$, and then used the textual meanings to let the students understand the distributive property in multiplication. The other question required the students to write word problems corresponding to " $\mathrm{a} \div \mathrm{b}+\mathrm{a} \div \mathrm{c}$ and $\mathrm{a} \div$ $(b+c)$," and then see whether the two equations were the same (L0525Ob).

\section{The Implementation of Mathematical Tasks by the Case Teachers}

Even though all three teachers used the implementation methods of group discussion, teacher-student dialogue, and individual practice, Lian's implementation of mathematical tasks was primarily based on group discussion (29/37). Mike's relied on mixed group discussion and teacher-student dialogue (8/32 and 17/32, respectively), and Yan focused on teacher-student dialogue (32/43). Seen from Table 3, Lian was inclined toward using cooperative learning to implement mathematical tasks, while Mike and Yan were inclined toward using teacher-student dialogue and direct presentation in their implementation.

Further analysis of the task implementation and types of mathematical tasks data showed that the mathematical tasks presented through group discussion were almost all high cognitive demand tasks, although the teachers differed on teacherstudent dialogue methods and the implementation of individual
Table 3.

Statistical summary of the teachers' implementation of mathematical tasks.

\begin{tabular}{lccc}
\hline Implementation of mathematical tasks & Lian & Mike & Yan \\
\hline Group discussion & 29 & 8 & 3 \\
Teacher-student dialogue & 5 & 17 & 32 \\
Individual practice & 3 & 7 & 8 \\
Total & 37 & 32 & 43 \\
\hline
\end{tabular}

practice. However, overall there were more low cognitive demand tasks than high cognitive demand tasks. Lian implemented 29 mathematical tasks using group discussion, of which 26 were high cognitive demand tasks and three were low cognitive demand tasks, such as asking the students to observe the changes in length and width of two photographs in the scale unit, which were low cognitive demand tasks using solutions created by known procedures (L0423Ob). In eight group discussion tasks, Mike implemented seven high cognitive demand tasks, of which one covered statistical chart manufacturing and computation (M0424Ob), which had low cognitive demand, as known procedures were used to solve single-step tasks. Yan implemented three group discussion tasks, all of which were high cognitive demand tasks.

Among the mathematical tasks implemented using teacherstudent dialogue, Lian administered four out of five low cognitive demand tasks, such as explanations on median and mode (L0312Ob). The coordinates unit used the dialogue method to request students to point out the coordinates of students and locations in the image (L0430Ob). Of Mike's 17 tasks, seven were low cognitive demand and ten are high cognitive demand, but only one allowed the students to engage in open observations and comparisons (shrunken images and scales unit, M0410Ob); the remaining nine were highly structured and guided by the teacher (cutting the task into several small tasks). Of Yan's 32 tasks, 20 were low cognitive demand and 12 were high cognitive demand, but ten were conducted with closed dialogue under highly structured guidance, and only two engaged in dialogue with open questions or emphasized connections, such as: "Hongjie says it took me 120 seconds to skate two laps, but Ziyi says it only took me 2.5 minutes to skate two laps. If you were the coach, who would you choose to be the skater" (Y0415Ob).

Regarding the tasks implemented through individual practice, Lian's three tasks were all low cognitive demand tasks. In Mike's seven tasks, five tasks were low cognitive demand and the other two were two-step word problems from the textbook (M0525Ob). Yan was unique, in that only two out of the eight individual practice tasks were low cognitive demand. The rest were open operations, observations, and comparisons (such as finding the center of a circle, Y0318O and the elements and rules for the formation of rectangles, Y0408Ob), or were twostep complex high cognitive demand tasks.

\section{Teacher-Student Interaction in Implementing Mathematical Tasks}

The methods of teacher-student interaction were affected by the methods of implementing the mathematical tasks. Those implemented through group discussion was open dialogue, which means the teachers asked open questions, the students 
could use the methods they understood to solve the tasks, as well as explain the complete thought processes and results of the solution. If the tasks were implemented using teacher-student dialogue, then it was primarily closed dialogue, which means the questions asked were closed with a fixed answer. In these situations the students used short answers rather than explaining their complete thought process for the solution. Of the 37 mathematical tasks, Lian had three individual practice tasks without any teacher-student interaction (the students practiced until the end of class, L0312Ob), and two group discussion tasks that were discussed until the end of class (L0226Ob, L0430Ob) and could not be counted. There were 27 tasks were group discussion mathematical tasks, all of which used open dialogue, asking each group to use their own methods and understanding to solve the tasks, and then providing the students with opportunities to completely solve the tasks as well as opportunities to ask questions. The other 5 tasks carried out through teacher-student dialogue, only one task asked the students to write word problems corresponding to the equation $(a+c) \times$ $b$ and then engage in open dialogue (L0521Ob), the other four carried out closed dialogue. Of the 32 mathematical tasks, Mike implemented eight group discussion tasks, which were all carried out through open dialogue, so that each group of students could have an opportunity to fully understand the solution process and results, as well as compare different solution methods and representations. There were 17 tasks implemented using teacher-student dialogue; however, 16 used closed dialogue as the interaction, and only one engaged in open interaction when asking the students to observe the similarities and differences between two similar images, at which time the students stated their complete thoughts (M0410Ob). As for individual practice tasks, other than two that used open dialogue in interaction (M0417Ob, M0525Ob), four were simple computational calculations or word problems. After the students finished solving the problems, Mike asked one student to write his solution on the board, and then closed dialogue was carried out on the student's solution. In addition, there was one practice question that did not have any interaction because the time ran out (M0313Ob). Of the 43 mathematical tasks, Yan implemented three group discussion tasks, which were all carried out through open dialogue, and another 32 were conducted using teacher-student dialogue. Even though the two tasks on speed provided students with the opportunity to fully explain the problem (only one student answered, Y0415Ob), later, Yan engaged in closed dialogue with the rest of the class based on the student's answers, so this was classified as closed dialogue. As for the eight individual practice tasks, two tasks did not have any interaction because the time ran out (Y0225Ob, Y0408Ob), and five used more open interaction, including using operations to find the center of a circle (Y0318Ob) or observing the elements that make up cubes (Y0408Ob). Only one was carried out using closed dialogue.

\section{Characterizing Teachers’ Mathematics Instruction Using Types of and Implementation of Mathematical Tasks}

Through the analysis the types of mathematical tasks implemented by the three teachers (high and low cognitive demand) and their presentation methods (open and closed dialogue), it was clear that the three teachers ustilized different types of mathematics instruction, as shown in Table 4.
Table 4.

Mathematics instruction of the three case teachers.

\begin{tabular}{lcccccc}
\hline Implementation & \multicolumn{3}{c}{ Open dialogue } & \multicolumn{3}{c}{ Closed dialogue } \\
\hline Task type & Lian & Mike & Yan & Lian & Mike & Yan \\
High cognitive & 25 & 10 & 9 & 0 & 10 & 9 \\
demand & 3 & 1 & 1 & 4 & 10 & 22 \\
Low cognitive demand & 3 &
\end{tabular}

Note: Discarding tasks without teacher-student interaction.

For Lian, of the 32 tasks that had teacher-student interaction, 25 were high cognitive demand mathematical tasks with open dialogue (including 24 group discussion tasks and one teacherstudent dialogue task, for $78 \%$ of the total). For three tasks, although they were implemented with group discussion, they were low cognitive demand tasks. For Mike and Yan, although 20 and 18 of the tasks were high cognitive demand tasks with teacher-student interaction, respectively, the students only learned 10 and nine tasks using high cognitive demand methods (Mike had seven group discussion tasks, one with teacher-student dialogue and two individual practice tasks, for 32\% of the total; Yan had three group discussion tasks, two teacher-student dialogue tasks, and four individual practice tasks, for $22 \%$ of the total). As for the rest, since the two teachers used closed dialogue implementation methods, many open observation and discussion or two-step high cognitive demand tasks had lowered difficulty due to closed dialogue and structural guidance, and the students used low cognitive demand methods to learn high cognitive demand mathematical tasks. On the whole, about $70 \%$ of these two teachers' mathematics instruction allowed the students to learn using low cognitive demand mathematical tasks or to use low cognitive demand methods to carry out the learning of high cognitive demand mathematical tasks.

Conversely, Lian did not use closed dialogue methods to implement high cognitive demand mathematical tasks, and used closed dialogue only for low cognitive demand tasks. For the high cognitive demand tasks, only one was implemented through teacher-student dialogues, in which the students were asked to write word problems that corresponded to $\mathrm{a} \times \mathrm{b}+\mathrm{c} \times \mathrm{b}$ or $(a+c) \times b$, and then carry out open dialogue to verify the meaning of the equations (L0521Ob); the others were implemented as group discussions.

In summary, based on the types of mathematical tasks implemented, Lian and Mike used many high cognitive demand tasks and Yan primarily used low cognitive demand tasks combined with other implementation methods. It was found that more than $70 \%$ of Lian's instruction allowed the students to learn high cognitive demand tasks with high cognitive demand methods, while $70 \%$ of Mike and Yan's instruction allowed the students to learn low cognitive demand tasks or use low cognitive demand methods to learn high cognitive demand tasks. Lian's tasks were primarily implemented as group discussions. Mike and Yan used teacher-student dialogue as the primary method of instruction in their implementation.

\section{Conclusion and Discussion}

The three case teachers presented mathematics instruction that did not fully conform to the trends and policy assertions of what mathematics instruction should look like in classrooms. Lian was the most inclined toward conforming to mathematics instruction policy recommendations, including adopting math- 
ematical tasks with high cognitive demands, using open questions to interact with the students, and giving the students opportunities to think and express their understanding. Of the mathematical tasks implemented by Mike and Yan, their instruction generally caused the students to learn mathematical tasks with low cognitive demand methods implemented by close dialogue. The different instructional methods of the three teachers were similar to the research findings of Artzt and Armour-Thomas (2002) in an instructional analysis of 14 middle school mathematics teachers in the United States. Three different instruction types were found in that study. One was student-centered, hoping that the students could achieve understanding in learning by providing mathematical tasks with suitable challenges. Another was teacher-centered, with an emphasis on procedural objectives and a focus on teaching the whole curriculum, without providing enough time for the students to express their own opinions or understanding. The final group was mixed, which sometimes is oriented toward students, and at other times is oriented toward the teachers. The trends and recommendations for mathematics instruction have created a beautiful picture for how the learning of mathematics can and should take place, but in Taiwan, how many teachers are teaching according to these reform recommendations? In the future, it will be necessary to further identify and understand the mathematics instruction of the majority of teachers in Taiwan, in order to serve as a basis for further exploration of how curricular or instructional reforms influence student mathematical learning.

Mathematical tasks are the core of student mathematical learning, and they affect student understanding of the nature of mathematics (NCTM, 1991). Thus, the past reform of mathematics curricula has focused on the presentation of mathematical tasks (Stein, et al., 2007). However, this study found that other than the types of mathematical tasks, a more crucial factor could be how teachers implement mathematical tasks. This is because even high cognitive demand tasks may be examined and solved by students using low cognitive demand methods because of the way teachers implement them in the classroom. Although the results of this study are similar to the research findings by Henningsen and Stein (1997), this study found that the main reasons for students interacting with the mathematical task types in low cognitive demand ways were because the teachers frequently reduced the complex high cognitive demand tasks into detailed closed questions with fixed answers, which replaced the possibility of student analysis of the tasks and decreased the opportunities for the students to explore and think about the whole task. Is this a common method employed by many teachers? This indicated that even though the type of mathematical task is important, the method of implementation is crucial. This study found that using group discussion to administer mathematical tasks generally required high cognitive processing on the part of the students, while closed dialogue tasks generally involved low cognitive processing. Does an intimate relationship exist between the two instructional approaches? This should be the foundation for further exploration of the relationship between the implementation of and the types of mathematical tasks.

\section{Acknowledgements}

This study was funded by the National Science Council under Grant No. NSC 97-2511-S-153-001. The authors would like to thank the on-site teachers and assistants who participated in this study. The viewpoints expressed in this article belong to the author and do not necessarily represent those of the $\mathrm{Na}-$ tional Science Council.

\section{REFERENCES}

Anderson, C. W. (2003). How can schools support teaching for understanding in mathematics and science? In A. Gamoran et al. (Eds.), Transforming: How schools and districts can support change (pp. 3-21). New York: Teachers College.

Artzt, A. F., \& Armour-Thomas, E. (2002). Becoming a reflective mathematics teacher: A guide for observations and self-assessment. Mahwah, NJ: Lawrence Erlbaum.

Becker, J. P., \& Selter, C. (1996). Elementary school, practices. In A. J. Bishop, K. Clements, C. Keitel, J. Kilpatrick, \& C. Laborde (Eds.), International handbook of mathematics education (pp. 511-564). Dordrecht: Kluwer Academic. doi:10.1007/978-94-009-1465-0_17

Boaler, J., \& Staples, M. (2008). Creating mathematical futures through an equitable teaching approach: The case of Railside school. Teacher College Record, 110(3), 608-645.

Boaler, J. \& Brodie, K. (2004). The importance, nature and impact of teacher questions. In D. E. McDougall, \& J. A. Ross (Eds.), Proceedings of the 26th Conference of the Psychology of Mathematics Education (North America, pp. 773-781). Toronto: OISE/UT.

Chung, C. (2005). Analyzing mathematics curriculum evolving of Taiwan in tens years. Journal of Education Research, 133, 124-134.

Cohen, D. K., \& Peterson, P. L., Wilson, S., Ball, D., Putnam, R., Prawat, R., Heaton, R., Remillard, J., \& Weimers, N. (1990). Effects of state-level reform of elementary school mathematics curriculum on classroom practice.

http://ncrtl.msu.edu/http/rreports/html/pdf/rr9014.pdf

Cowan, P. (2006). Teaching mathematics: A handbook for primary and secondary school teachers. London: Routledge. doi:10.4324/9780203416013

Feldman, A. (2003). Mathematics instruction: Cognitive, affective, and existential perspectives. In J. M. Royer (Ed.), Mathematics cognition. Greenwich, CT: Information Age.

Fuson, K. C., et al. (2000). Blending the best of the twentieth century to achieve a mathematics equity pedagogy in the twenty-first century. In M. J. Burke, \& F. R. Curcio (Eds.), Learning mathematics for a new century (pp. 197-212). Reston, VA: NCTM.

Grouws, D. A., Smith, M. S., \& Sztajn, P. (2004). The preparation and teaching practice of U.S. Mathematics teachers: Grades 4 and 8. In P. Kloosterman, \& F. Lester (Eds.), The 1990 through 2000 mathematics assessments of the National Assessment of Educational Progress: Results and interpretations (pp. 221-269). Reston, VA: NCTM.

Gutstein, E. (2003). Teaching and learning mathematics for social justice in an urban, Latino school. Journal for Research in Mathematics Education, 34, 37-73. doi:10.2307/30034699

Henningsen, M., \& Stein, M. K. (1997). Mathematical tasks and student cognition: Classroom-based factors that support and inhabit highlevel mathematical thinking and reasoning. Journal for Research in Mathematics Education, 28, 524-549. doi:10.2307/749690

Hiebert, J., \& Grouws, D. A. (2007). The effects of classroom mathematics teaching on students’ learning. In F. K. Lester Jr. (Ed.), Second handbook of research on mathematics teaching and learning (pp. 371-404). Gweenwich, CT: Information Age.

Kilpatrick, J., \& Silver, E. A. (2000). Unfinished business: Challenges for mathematics educator in the next decades. In M. J. Burke, \& F. R. Curcio (Eds.), Learning mathematics for a new century (pp. 223235). Reston, VA: NCTM.

Lott, J. W., \& Souhrada, T. A. (2000). As the century unfolds: A perspective on secondary school mathematics content. In M. J. Burke, \& F. R. Curcio (Eds.), Learning mathematics for a new century (pp. 96-111). Reston, VA: NCTM.

Ministry of Education in Taiwan (2003). The learning domain of mathematics of grade 1-9 curriculum guidelines. Taipei: Ministry of Education.

Mullis, I. V. S., Martin, M. O., Gonzales, E. J., \& Chrostowski, S. J. 
(2004). TIMSS 2003 international mathematics report: Findings from IEA's trends in international mathematics and science study at the fourth and eighth grades. Chestnut Hill, MA: TIMSS \& PIRLS International Study Center.

NCTM (1991). Professional standards for teaching mathematics. Reston, VA: NCTM.

NCTM (2000). Principles and standards for school mathematics. Reston, VA: NCTM.

Rodriguez, A. J. (2005). Teachers' resistance to ideological and pedagogical change: Definitions, theoretical framework, and significance. In A. J. Rodriguez, \& R. S. Kitchen (Eds), Preparing mathematics and science teachers for diverse classrooms: Promising strategies for transformative pedagogy (pp. 1-16). Mahwah, NJ: Laurence Erlbaum.

Silver, E. A., Mesa, V. M., Morris, K. A., Star, J. R., \& Benken, B. M. (2009). Teaching mathematics for understanding: An analysis of lessons submitted by teachers seeking NBPTS certification. American Educational Research Journal, 46, 501-531. doi:10.3102/0002831208326559
Stein, M., Smith, M., Henningsen, M., \& Silver, E. (2000). Implementing standards-based mathematics instruction: A casebook for professional development. New York: Teacher College.

Stein, M. K., Remillard, J., \& Smith M. S. (2007). How curriculum influences student learning. In F. K. Lester Jr. (Ed.), Second handbook of research on mathematics teaching and learning (pp. 319369). Gweenwich, CT: Information Age.

Verschaffel, L., \& De Corte, E. (1996). Number and arithmetic. In A. J. Bishop, K. Clements, C. Keitel, J. Kilpatrick, \& C. Laborde (Eds.), International handbook of mathematics education (pp. 99-137). Dordrecht, Netherlands: Kluwer Academic. doi:10.1007/978-94-009-1465-0 5

Weiss, I. R., Banilower, E. R., McMahon, K. C., \& Smith, P. S. (2001) Report of the 2000 national survey of science and mathematics education. Chapel Hill, NC: Horizon Research.

Willoughby, S. S. (2000). Perspectives on mathematics education. In M. J. Burke, \& F. R. Curcio (Eds.), Learning mathematics for a new century (pp. 1-15). Reston, VA: NCTM. 